\title{
Effect of demand response on the marginal electricity used by plug-in electric vehicles
}

\author{
David Dallinger ${ }^{1}$, Martin Wietschel ${ }^{1}$, Danilo J. Santini ${ }^{2}$ \\ ${ }^{1}$ David Dallinger, Professor Martin Wietschel, Fraunhofer Institute for Systems and Innovation Research. \\ Contact address: Breslauer Str. 48, 76139 Karlsruhe, Germany, e-mail: david.dallinger@isi.fraunhofer.de \\ ${ }^{2}$ Danilo J. Santini, Argonne National Laboratory, Transportation Technology R\&D Center
}

\begin{abstract}
Plug-in electric vehicles (PEV) are considered to be a potentially sustainable alternative to conventional vehicles for private transport and a way of balancing intermittent generation from renewable energy sources (RES). Using RES for electric mobility would be superior to all available fossil generation alternatives in terms of emissions and efficient energy conversion. To quantify the marginal energy from RES used, two charging strategies last trip charging and optimized demand-side management (DSM) with dynamic pricing are investigated for a German long-term high RES power mix scenario. The results for both charging cases indicate that the power demand for PEVs will not be met by RES. For last trip charging $1.40 \%$ comes from RES. In terms of DSM this share increases to $7.38 \%$ but results in higher overall $\mathrm{CO}_{2}$ emissions because for Germany coal provides the lowest cost fossil power. Hence DSM charging reduces peak load and helps to balance RES generation but is contrary to the original idea of clean transportation because of higher marginal emissions caused by the utilisation of coal.

To account for contractual arrangements allowing consumers to directly purchase RES electricity, a second scenario with additional installed RES capacity is analysed. Because of the high RES share of over $50 \%$ a complete usage of the RES is not possible and a small fraction of power must still be provided by dispatchable power plants. For the second scenario, DSM charging also allows for an increased use of RES compared to last trip charging ( $99 \%$ versus $90 \%$ RES). In addition, total marginal $\mathrm{CO}_{2}$ emissions are lower and DSM helps to balance the ramping of RES. Therefore, it is concluded that for Germany the installation of additional RES and DSM charging would guarantee clean transportation using electric vehicles.

Keywords: Plug-in electric vehicles, $\mathrm{CO}_{2}$ emissions, renewable energy supply
\end{abstract}

\section{Introduction}

The greenhouse gas emissions of plug-in hybrid electric vehicles and/or battery electric vehicles (PEVs) are unquestionably determined to a large extent by how the electricity is generated. However, the usual least cost marginal dispatch method of assigning generation to various loads may not assign renewable energy sources (RES) as the provider of electrical energy to PEVs, even if the timing of RES generation and charging are coincident. The following discussion focuses on two methods of assignment of electricity generation mix for PEVs, under circumstances where (1) PEV owners leave the selection of generator to the system operator versus (2) the PEV owner contracts only for purchase of RES for charging. The paper does not consider the complete life cycle of electric vehicles including vehicle and battery production as well as recycling and transportation issues. A general literature analysis reveals that the emissions during the production of electric vehicles are higher than for conventional vehicles because of 
Figure 1: Comparison of tank-to-wheel $\mathrm{CO}_{2}$ emissions with different fuels and conversion technology

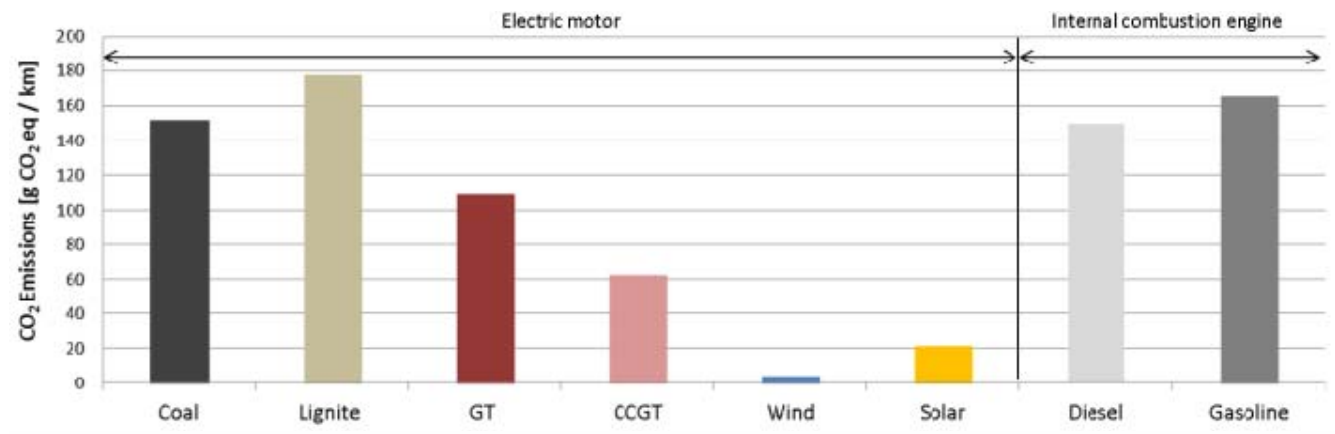

Assumptions: Efficiency: gas turbine (GT) 37\%; combined cycle gas turbine (CCGT) 64.5\%; coal power plant 46.5\%; lignite power plant 45\%; electric drive train $90 \%$; diesel engine $0.32 \%$; gasoline engine $28 \%$. Energy use at the wheel $0.18 \mathrm{kWh} / \mathrm{km}$. Emission factors [ $\mathrm{CO}_{2}$ eq $\left./ \mathrm{kWh}\right]:$ gas 201.6; coal 352.8; lignite 399.6, oil 266.4; wind 21; solar 106. (For literature on emission factors see e.g. [4]).

battery production (see [1-3]). It is therefore even more important to use clean electricity to power the vehicles.

Figure $1^{1}$ illustrates our estimates of the fuel and/or technology pathway averages of tank-towheel $\mathrm{CO}_{2}$ emissions of the electric drive train compared to conventional vehicles. A strong variation depending on the fuel used can be observed for the conversion of electricity. Fossil fuels, especially coal and lignite, do not considerably alter PEV emissions per kilometre relative to conventional vehicles. Only a very efficient conversion technology, using combined cycle gas turbines and renewable energy sources such as wind and solar, can reduce PEV emissions significantly. The wide span between lignite and wind also underlines the importance of the electricity source for the life cycle analysis.

The effect of the PEVs' demand on the power system has been examined by various studies (e.g. see [5], [6] and [7]). These studies show that the results are strongly influenced by the merit order, which depends mainly on the power plant efficiencies and fuel prices as well as the load curve to which the PEVs' demand is added. Further, [7] indicates it is theoretically possible to dispatch clean power plants if the system operator is the only player in the market or if emission taxes are included. In contrast to previous studies, the present analysis also considers a power system base case with a high share of RES. Such a system is distinguished by its low utilization of base load power plants.

Due to the adoption of RES, the variability of fossil power plant load increases under all circumstances. In other words, the residual load varies over the total merit order. Hence, there is a much higher probability that base load power

\footnotetext{
1 Because of assumptions on efficiency and emissions factors values can vary in the range of 10 to $20 \%$.
}

plants and even RES will be the marginal power plant. It seems very likely that, without very high emission taxes, coal will dominate [8] the lower price part of the merit order in the future in Germany. These and other results imply that PEVs using smart charging where coal provides a significant portion of generation will not reduce the $\mathrm{CO}_{2}$ emissions of the transportation sector $[9,10]$ (also see Figure 2). It may be deduced that RES are necessary to fuel PEVs in order to achieve a significant reduction of $\mathrm{CO}_{2}$ emissions unless nuclear power instead of coal provides most base load capacity. This paper addresses the behaviour of an electric generation mix where coal dominates current base load capacity while RES additions are considered highly desirable, so RES achieves a very high share of generation. This very high use of RES drives down the capacity utilization of base load (coal) power plants. Consequently, nuclear power plants cannot be competitive because they do not realize sufficient revenue to offset their higher initial costs.

The paper is structured as follows. Section 1 introduces an hourly resolved energy system model. A 2030 scenario is then developed for Germany based on the assumptions about the power plant park, the RES in the electricity system and the penetration of plug-in hybrids (PHEVs) and battery electric vehicles (BEVs) summarized in Section 2. The marginal $\mathrm{CO}_{2}$ emissions resulting from the five simulations are presented in Section 3. Finally, Section 4 provides several conclusions.

\section{Model approach}

The effects of PEVs on the electricity system are investigated by combining the following approaches: a stochastic model to determine mobility behavior, an optimization model to 


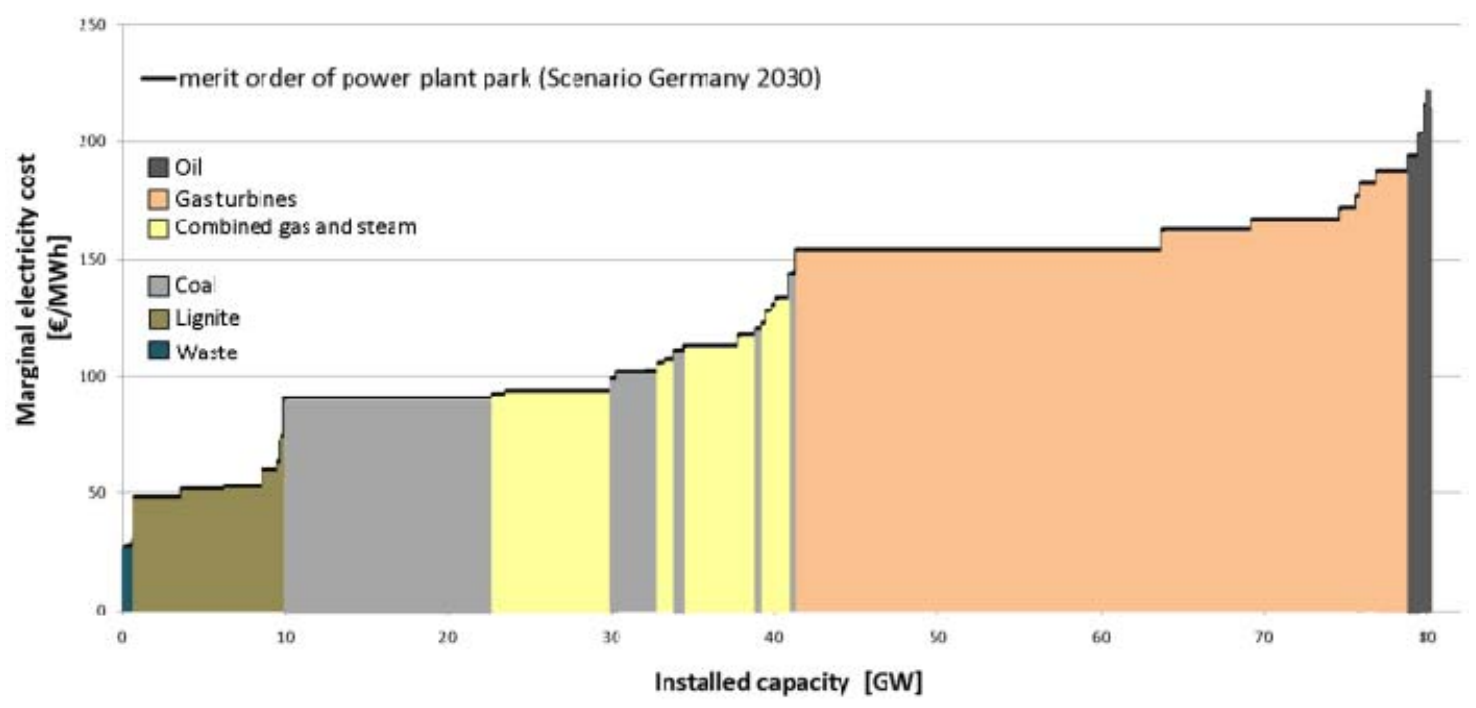

Source: Own calculations and [10]; assumed prices: $\mathrm{CO}_{2}=52 € / \mathrm{t}$, coal $=23.4 € / \mathrm{MWh}$, lignite $=3.8 € / \mathrm{MWh}$, gas $=49.68 € / \mathrm{MWh}$, oil $=58.68$ $€ / \mathrm{MWh}$; installed capacity: oil $0.7 \mathrm{GW}$; gas turbines $38.2 \mathrm{GW}$; combined gas and steam $1.6(\eta=45-59)$ and $13.8 \mathrm{GW}(\eta=60-65)$; coal 14.9 $\mathrm{GW}$, lignite $9.2 \mathrm{GW}$; waste $0.8 \mathrm{GW}$.

minimize vehicle charging costs, and an agentbased electricity market equilibrium model to estimate variable electricity prices and power plant utilization $\left[\begin{array}{lll}11 & \& & 12\end{array}\right]$. The variable electricity prices are calculated based on marginal generation costs. The marginal costs of intermittent RES are very low and assumed to be zero. Hence, the estimated electricity prices provide incentives to consume electricity when the supply of renewable generation is high. Ramping constraints are considered by using start- up costs. We distinguish two cases of PEV charging demand: after the last trip (Last trip) and demand side management (DSM). In the DSM case, vehicles minimize costs of their electricity consumption according to the price signal. An important attribute of PEVs is that the vast majority of their daily $\mathrm{kWh}$ needs can be met by charging overnight. With charger $\mathrm{kW}$ ratings assumed here, the timing of charging can be varied significantly within the overnight hours. A charging option not evaluated here is to specify achievement of a full charge just prior to morning departure [13 \& 14]. The market equilibrium model used here is very detailed. It calculates the exact utilization of power plants for all 8760 hours a year. Comparing simulation runs with and without PEVs shows how much power each plant provides to operate the PEV fleet.

Using this approach we address the following issues:

- Estimating PEV $\mathrm{CO}_{2}$ emissions when fossil power plants serve most PEV needs under least marginal cost dispatch.

- Analyzing which fossil power plants still must be utilized even though additional energy is required to be provided by RES with the intention to equal the amount consumed by the PEVs.
- In both of the scenarios above, for the DSM vs. Last trip charging strategies, investigating the effect of RES added by DSM on the $\mathrm{CO}_{2}$ emissions.

\section{Assumptions}

To compare the electricity produced for PEVs, we distinguish two scenarios: (1) least cost marginal dispatch of a fixed amount of existing RES capacity using existing fossil generators to meet additional PEV loads, or (2) incremental capacity investment and generation to serve additional PEV loads, contractually dedicated only to RES. For scenario (1) and (2), a conventional power plant mix (see Figure 2) is selected using a cost minimization approach which is based on the fuel and $\mathrm{CO}_{2}$ prices assumed in 2030. The power plant park of dispatchable capacity is unchanged for both scenarios. In scenario (1), a RES share of 62 percent of the electricity produced is assumed $[15]^{2}$. Additional RES capacity to serve for scenario (2) originates from wind onshore, wind offshore and photovoltaic generation. In both scenarios, an increase of PEV demand of 19.16 TWh for last trip charging and 24.79 TWh for DSM is assumed. The larger PEV TWh for the DSM assumption is enabled by a higher availability of free charging infrastructure (at home and at work). In terms of last trip charging a PEV consequently charges only once a day whereas DSM allows for multiple charging opportunities, diurnal load shifting, and even dayto-day shifting.

\footnotetext{
${ }^{2}$ Wind onshore $37.8 \mathrm{GW}$, wind offshore $25 \mathrm{GW}$, photovoltaic 63 $\mathrm{GW}$ additionally hydro, biomass and geothermal energy production are considered (for details see [15]).
} 
Figure 3: Source of electricity for plug-in electric vehicles in percent

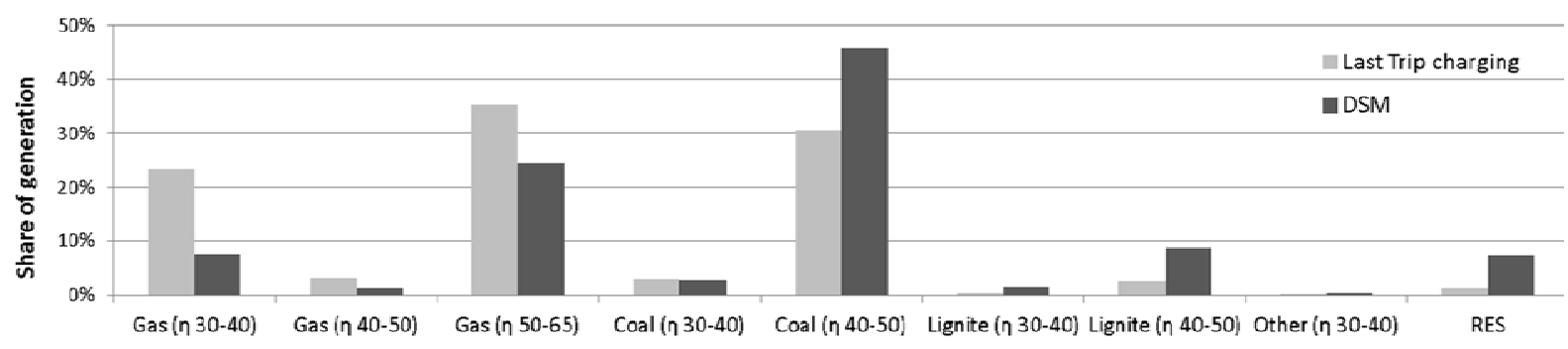

The PEV penetration scenario follows [17], which studies a $100 \%$ penetration of alternative vehicles (HEVs, PHEVs, BEVs and FCV) ${ }^{3}$ in Japan in 2050. The penetration of PHEVs and BEVs was adapted to the German passenger vehicle market. The electric vehicle concepts distinguish PHEVs with $4.5 \mathrm{kWh}$ or $12 \mathrm{kWh}$ and BEVs with $15 \mathrm{kWh}$ or $30 \mathrm{kWh}$ usable battery storage (see Table 1). Although the PEVs in Table 1 would typically be parked overnight for 9 or more hours, the charger $\mathrm{kW}$ capabilities allow charging in a much shorter time, creating the possibility to vary both timing and rate of charging while still meeting the PEV customer's needs.

Table 1: Passenger vehicle types

\begin{tabular}{cccccc}
\hline Device & Type & $\begin{array}{c}\text { Usable } \\
\text { storage } \\
\text { [kWh] }\end{array}$ & $\begin{array}{c}\text { Grid } \\
\text { connection } \\
\text { power [kW] }\end{array}$ & $\begin{array}{c}\text { Equivalent } \\
\text { energy use } \\
{\left[\mathbf{k W h}_{\mathbf{e}} / \mathbf{k m} \text { ] }\right.}\end{array}$ & $\begin{array}{c}\text { GER 2030 } \\
\text { (12 million } \\
\text { PEVs) }\end{array}$ \\
\hline 1 & $\begin{array}{c}\text { PHEV } \\
(25)\end{array}$ & 4.5 & 4 & 0.18 & $31.60 \%$ \\
2 & $\begin{array}{c}\text { PHEV } \\
(57)\end{array}$ & 12 & 4 & 0.21 & $50.40 \%$ \\
3 & $\begin{array}{c}\mathrm{BEV} \\
(100)\end{array}$ & 15 & 8 & 0.15 & $13.90 \%$ \\
4 & $\begin{array}{c}\mathrm{BEV} \\
(167)\end{array}$ & 30 & 8 & 0.18 & $4.00 \%$ \\
\hline
\end{tabular}

With regard to PEVs' energy use, it is assumed there is a reduction in weight as well as in air and rolling resistance compared to today's average vehicles ${ }^{4}$. The total PEV penetration in 2030 is 12 million or $24 \%$ of the total passenger vehicle fleet, with PHEVs accounting for over $80 \%$ of PEVs (69\% of useable fleet storage capacity)

\section{Results}

\subsection{Scenario 1: - Least Marginal Cost Dispatch}

The PEV's marginal energy source is given by the differences in power plant generation between the simulations excluding and including PEVs. Table 2 shows three energy balances for the simulation

\footnotetext{
3 HEV: Hybrid Electric Vehicle, PHEV: Plug-in Hybrid Electric Vehicle, BEV: Battery Electric Vehicle and FCV: Fuel Cell Vehicle.

4 Values in the weight range $800-1400 \mathrm{~kg}$, drag coefficient $0.2-$ 0.26 and rolling resistance $0.0045-0.006$. For details on the fuel consumption of PEVs see [18], [19] and [20].
}

- excluding PEVs, last trip charging and DSM. In terms of generation, fossil and renewable energy sources (RES) are distinguished, as is the total annual negative residual load ${ }^{5}$. Negative residual load occurs when RES generation exceeds all system needs. It requires transmission and sales outside of the system, and/or curtailment of RES, both of which add cost. The reduction of the negative residual load between the scenarios including and excluding PEVs is due to the marginal electricity consumed by PEVs from RES. For last trip charging, this reduction is 0.27 TWh of 19.16 TWh total demand for the last trip case, increasing to $1.81 \mathrm{TWh}$ of $24.79 \mathrm{TWh}$ total demand for DSM. The implication is that DSM with least marginal cost dispatch actually increases the match of wind generation to PEV charging, in comparison to the last trip charging profile. However, it is also true that the total PEV TWh increases in the DSM case, and this probably also provides a negative residual load reduction benefit. Although PEVs' marginal generation is dominated by fossil fuels with 18.9 TWh and $22.98 \mathrm{TWh}$ in the two charging cases, it is nevertheless true that the simulated system takes advantage of RES support at times.

Table 2: Energy balance for fixed RES with either last trip charging or demand side management (DSM) for SCENARIO 1 GERMANY 2030

\begin{tabular}{c|ccc|cc|cc}
\hline & \multicolumn{3}{|c|}{ Generation } & \multicolumn{2}{c|}{ Load } & \multicolumn{2}{c}{$\begin{array}{c}\text { PEVs energy } \\
\text { source }\end{array}$} \\
Unit [TWh] & Fossil & RES & $\begin{array}{c}\text { Neg. } \\
\text { residual } \\
\text { load }\end{array}$ & Total & PEVs & Fossil & RES \\
\hline $\begin{array}{c}\text { Excluding } \\
\text { PEVs }\end{array}$ & 179.35 & 325.15 & -3.02 & 502.10 & & & \\
Last trip & 198.15 & 325.15 & -2.75 & 521.26 & 19.16 & 18.90 & 0.27 \\
DSM & 202.19 & 325.15 & -1.21 & 526.89 & 24.79 & 22.98 & 1.81 \\
\hline
\end{tabular}

Fossil generation for last trip charging is dominated by gas as a primary energy source (see Figure 3). Smart charging or DSM shifts demand to hours with lower marginal costs. Typically, in these hours, the marginal power plant is one with higher $\mathrm{CO}_{2}$ emissions such as coal, or, for

\footnotetext{
Negative residual load is RES generation not usable within the simulation limits. Negative residual load occurs if RES generation exceeds the demand.
} 
Figure 4: Change in electricity production by source while installing additional renewable energy sources to cover the demand of electric vehicles. Note: Unit of values TWh

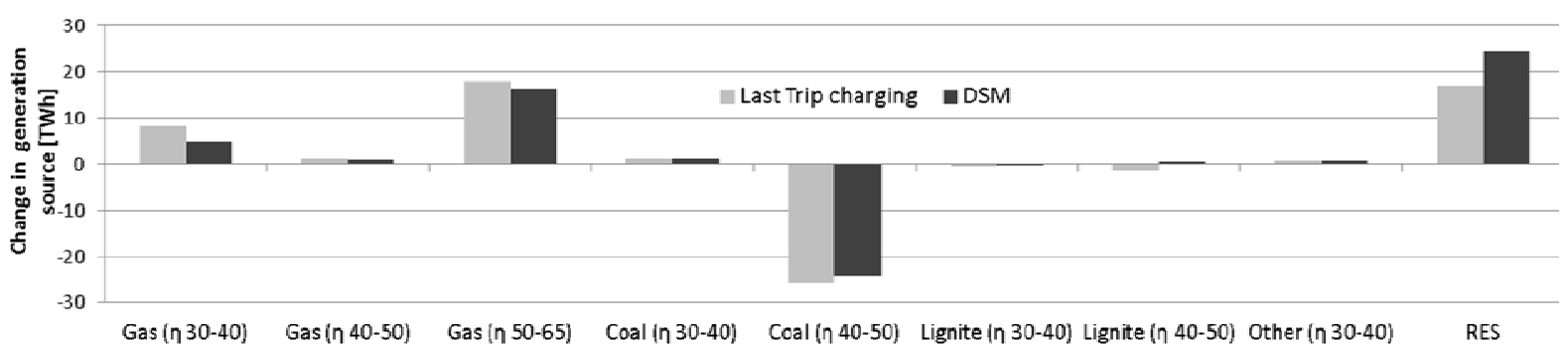

Germany, lignite (see Figure 2). The fossil generation mix of PEVs using DSM therefore is dominated by coal (see Figure 3). DSM and increased PEV demand together increase the share of RES $(7.38 \%$ versus $1.40 \%)$. DSM reduces the peak load and balances the intermittency in the grid (see [12]). However, with the given power plant park, DSM also increases total $\mathrm{CO}_{2}$ emissions. This pattern was also seen in U.S. simulations for regions that are coal dependent [9, 10]. The specific $\mathrm{CO}_{2}$ emissions for electricity generated to provide for last trip charging are $558.21 \mathrm{~g} / \mathrm{kWh}$. For DSM they increase to 614.19 $\mathrm{g} / \mathrm{kWh}$. The increase in the fraction of marginal RES generation is not large enough to compensate for the increase in the share of $\mathrm{CO}_{2}$-intensive base load power plants. Assuming energy use of 0.2 $\mathrm{kWh} / \mathrm{km}$, emissions per kilometer of average PEV driving are $111.64 \mathrm{~g} / \mathrm{km}$ for last trip and 122.84 $\mathrm{g} / \mathrm{km}$ for DSM charging. These values are in the range of today's efficient passenger vehicles using combustion engines. They are somewhat lower than the average combustion engine vehicles projected for 2030 in Fig. 1. As was estimated for the U.S. $[9,10]$, there must be a significant share of natural gas generation to bring PEV electric driving $\mathrm{CO}_{2}$ averages estimated using least marginal cost dispatch below estimates for conventional vehicles

\section{Scenario 2: Construction and Dispatch of RES to Serve PEVs}

Many utilities in the United States have set up legal frameworks under which consumers may contract to purchase electric power that is nominally purely from RES. These programs are described as "an optional utility service that allows customers to support a greater level of utility investment in renewable energy by paying a premium on their electric bill to cover any above-market costs of acquiring renewable energy resources" [21]. These programs give purchasers of PEVs who may wish to do so the opportunity to pay more to minimize their $\mathrm{CO}_{2}$. Nominally, the electricity needed would be provided from additionally installed RES $^{6}$. However, critics might argue that the actual timing of the RES generation would not match the charging time of the PEVs. However, as we have noted, the timing of overnight charging of a PEV can technically be quite flexible. A great deal of flexibility is already built into the charge timing set up options available to PEV owners. General Motors and Google are working together to provide a capability to make charge rates track the availability of RES, by obtaining wireless information on RES generation shares from the system operator [22]. We assume in this analysis that automated real time control of charging of PEVs is possible at reasonable cost in 2030, by using an assumption of very elastic real time response to independent system operator (ISO) control signals. We represent a scenario where consumers (or possibly governments via regulation [23]) demand to have their PEVs and RES be a part of a linked system designed to minimize fossil fuel use. As in scenario 1, 19.16 TWh (last trip) and 24.79 TWh (DSM) of additional energy are required to serve PEVs. This energy is legally obligated to come from RES. However, even with additional RES, it is technically not possible for the simulated system to provide all of the power needed to drive renewably. Intermittent RES supply does not necessarily match PEVs' demand. Nevertheless, it should be noted that the timing of wind availability and charge acceptance from a fleet of PEVs can be matched better, with less consumer inconvenience, than any other electrical appliance that will be in use in 2030. A good match was found by J. Wang et al for Illinois in the U.S. [16]. In this analysis, for last trip charging, net generation of only 1.96 TWh or about $10 \%$ of the electricity still has to be provided by conventional power plants. For DSM, the net fossil energy

\footnotetext{
6 The German government has announced that the electricity for
} electric vehicles should come from additional RES. 
needed is only $0.16 \mathrm{TWh}$ or less than $1 \%$ (see Table 3, Fig. 4).

For scenario 2 it is not possible to unequivocally decompose the mix of electricity needed from controllable power plants due to two overlapping effects. First, the additional RES generation replaces controllable generation and, second, a small fraction of electricity from controllable power plants is still consumed by PEVs. The approach used does not allow these two effects to be separated. The change in electricity produced compared to the simulation without PEVs (see Figure 4) indicates that the additional RES mainly replaces coal with generation from gas-fired power plants. For DSM, less coal is replaced (24.3 TWh reduction versus $25.53 \mathrm{TWh}$ reduction).

Table 3: Energy and emission values for the RES legally equals PEV requirements scenario

\begin{tabular}{|c|c|c|c|c|c|c|c|}
\hline & \multicolumn{3}{|c|}{ Generation [TWh] } & \multicolumn{2}{|c|}{$\begin{array}{c}\text { PEVs energy } \\
\text { source } \\
\text { [TWh] }\end{array}$} & \multicolumn{2}{|c|}{$\begin{array}{c}\mathrm{CO}_{2} \text { emissions } \\
{[\mathrm{g} / \mathrm{kWh}]}\end{array}$} \\
\hline & Fossil & RES & $\begin{array}{c}\text { Neg. } \\
\text { Residual } \\
\text { load } \\
\end{array}$ & Fossil & RES & Thermal & Total \\
\hline $\begin{array}{l}\text { Excluding } \\
\text { PEVs }\end{array}$ & 179.35 & 325.15 & -3.02 & & & 766.60 & 273.82 \\
\hline Last trip & 181.31 & 344.27 & -5.08 & 1.96 & 17.20 & 710.87 & 247.26 \\
\hline DSM & 179.50 & 349.89 & -3.22 & 0.16 & 24.64 & 720.38 & 245.42 \\
\hline
\end{tabular}

In terms of $\mathrm{CO}_{2}$ emissions, the average emissions of the thermal power plants are $710.87 \mathrm{~g} / \mathrm{kWh}$ for last trip charging and $720.38 \mathrm{~g} / \mathrm{kWh}$ for DSM. An emission reduction is achieved compared to the simulation without PEVs $(766.6 \mathrm{~g} / \mathrm{kWh})$. These average emissions of fossil generation, when combined with the defined RES mix of wind and photovoltaic generation results in $\mathrm{CO}_{2}$ emissions of $117.1 \mathrm{~g} / \mathrm{kWh}$ for last trip charging and 55.5 $\mathrm{g} / \mathrm{kWh}$ for DSM. The emissions are 23.4 and $10.7 \mathrm{~g} \mathrm{CO}_{2}$ equivalent per $\mathrm{km}$ for last trip charging and DSM, respectively, a nearly complete reduction compared to conventional vehicles.

\section{Conclusions}

This paper investigates the utilization of thermal power plants and renewable energy sources including and excluding the electricity demand of plug-in electric vehicles in Germany. Compared to approaches which use the average $\mathrm{CO}_{2}$ emissions of the power plant park, the methods used here allow the electricity consumption of electric vehicles to be directly assigned to individual power plants and therefore provide much more accurate results. In scenario 1 this work reproduces results obtained in similar least marginal cost simulations in the U.S. To the best of our knowledge, this paper is the first to examine the technical allocation of generation energy to PEVs that are required either by regulation or contract to be served by RES. It is found in this simulation that the legal fiction that PEVs could entirely be served by RES under such operational targets is not terribly inaccurate. The conclusions in detail are:

- For the case study made, but also for other electricity systems, the $\mathrm{CO}_{2}$ emissions from the power plants allocated to PEVs via "smart charging" using least marginal cost can be higher than the average of the total power plant $\operatorname{mix}^{7}$, particularly if coal dominates base-load generation capacity [5, 9, 10]. A higher share of renewable energy sources (RES) magnifies this effect because RES only very rarely function as the marginal power plant.

- On the one hand, least marginal cost smart charging or DSM, in comparison to uncontrolled last trip charging, increases the share of RES as real time dynamic price signals cause variable charging rate increases when wind is available, in order to reduce net costs. In our scenario 1 case study an increase of RES from $1.40 \%$ to $7.28 \%$ was simulated via adoption of sophisticated dynamic DSM. On the other hand, such smart charging also results in a higher utilization of coal power plants due to their low marginal costs and the reduced variability of RES load, net of charging. $\mathrm{CO}_{2}$ is increased because of the resulting higher utilization of coal and lignite which have very high $\mathrm{CO}_{2}$ emissions (negative effect). In detail, electric driving results in $112 \mathrm{~g} \mathrm{CO}_{2}$ equivalent per kilometer for last trip and $123 \mathrm{~g} \mathrm{CO}_{2}$ equivalent per kilometer for smart charging. Either value is a minor emission reduction compared to conventional vehicles.

- A higher utilization of base load power plants can be positive in terms of $\mathrm{CO}_{2}$ emissions if combined cycle gas turbines or combined heat and power serve base load requirements [7]. Aside from the United States, where shallow, inexpensive shale gas has driven supply estimates up while expanding production has driven the price of natural gas down sharply [24], the expected price spread

\footnotetext{
This study excludes nuclear power because the planned nuclear phase out in Germany and $\mathrm{CO}_{2}$ sequestration because of the very high costs resulting from a low utilization in systems with a high RES share and technology uncertainty.
} 
between coal and gas as well as the installation of new power plants in the past [8] indicate that coal is likely to be dispatched as the marginal power plant for smart charging PEVs in many power systems of the world.

- To improve the life cycle emissions of electric vehicles, governments, automotive companies and consumers are considering the installation and, in some cases, exclusive use of additional RES. In scenario 2 this exclusive RES use strategy was simulated to result in a significant reduction of $\mathrm{CO} 2$ emissions. DSM via dynamic smart charging and higher TWh of PEV use together achieved higher RES use and thus an even greater $\mathrm{CO}_{2}$ reduction than last trip charging (10.7 versus $23.4 \mathrm{~g}$ CO2 equivalent per kilometer). The largest reductions resulted when a dynamically controllable smart charging system was implemented, because even less controllable fossil power was needed. Although the $\mathrm{CO} 2$ percentage improvement from DSM instead of last trip charging is large, the added change relative to overall reduction from a gasoline vehicle is not particularly large. The greatest benefit comes from the commitment to build RES to serve PEVs.

The paper confirms the importance of the future choice of electricity source in terms of the life cycle emissions from a relatively large fleet of PEVs. The paper shows that, according to least marginal cost principles of power plant dispatch, in an environment with a very high share of previously mandated RES with smart, dynamic charging, and significant coal capacity, standard estimates of marginal $\mathrm{CO}_{2}$ emissions for electric driving can be very high. Significant emission reductions are possible and logically attributable to RES if RES generators are dedicated for use to provide electricity to the PEVs. In scenario 2, which is more costly than scenario 1's use of existing fossil power plants to charge PEVs, the incremental capital investment for PEV charging chosen by consumers and/or governments despite its higher fully allocated cost - was RES. The reward would be nearly fossil free transportation service from the plug, reducing oil imports, greenhouse gases and tailpipe emissions.

\section{Acknowledgements}

Dr. Santini would like to gratefully acknowledge the sponsorship of David Howell, Team Leader,
Hybrid and Electric Systems, Office of Vehicle Technology, U.S. Department of Energy.

The work of Martin Wietschel and David Dallinger has been co-financed by a grant of the German Federal Ministry for the Environment, Nature Conservation and Nuclear Safety (BMU) as part of the project "Flottenversuch Elektromobilität". The authors would like to thank Patrick Plötz, Till Gnann and Gillian BowmanKöhler for discussions and critical reading of the manuscript.

\section{References}

[1] H. Helms, M. Pehnt, U. Lambrecht and A. Liebich, Electric vehicle and plug-in hybrid energy efficiency and life cycle emissions, 18th International Symposium Transport and Air Pollution, 2010

Retrieved: 11 July 2011, URL:

http://www.ifeu.de/verkehrundumwelt/pdf/H elms $\% 20$ et $\% 20$ al. $\% 20 \% 282010 \% 29 \% 20$ Ele ctric\%20vehicles $\% 20 \% 28 \mathrm{TAP} \% 20$ conferen ce $\% 20$ paper $\% 29 \% 20$ final.pdf.

[2] CONCAWE, Tank-to-Wheels Reports, Appendix 1: Vehicle retail price estimation, Version 2c, March 2007, Concawe, European Council for Automotive R\&D, European Commission Joint Research Center. Retrieved: 11 July 2011, URL: http://ies.jrc.ec.europa.eu/wtw.html, Retrieved: 10.09.2008.

[3] Burnham, A., M. Wang and Y. Wu. Development and Applications of GREET 2.7. The Transportation Vehicle Cycle Model. Argonne National Laboratory Report ANL/ESD/06-5. Argonne, IL (Nov. 2006).

[4] M. Lenzen, Life cycle energy and greenhouse gas emissions of nuclear energy: A review, Energy Conversion and Management 49, 2008, pp. 2178-2199.

[5] K. Parks, P. Denholm, T. Markel, Costs and Emissions Associated with Plug-In Hybrid Electric Vehicle Charging in the Xcel Energy Colorado Service Territory Costs and Emissions Associated with Plug-In Hybrid Electric Vehicle Charging in the Xcel Energy Colorado Service Territory, Technical Report. NREL/TP-640-41410, May 2007.

[6] R. McCarthy, C. Yang, C., Determining marginal electricity for near-term plug-in and fuel cell vehicle demands in California: impacts on vehicle greenhouse gas 
emissions, Journal of Power Sources 195, April 2010, pp. 2099-2109.

[7] Ramteen Sioshansi, Jacob Miller, Plug-in hybrid electric vehicles can be clean and economical in dirty power systems. Energy Policy 39 (10), October 2011, pp. 61516161. doi:10.1016/j.enpol.2011.07.015. http://linkinghub.elsevier.com/retrieve/pii/S0 301421511005386

[8] International Energy Agency, World Energy Outlook 2011, WEA, Paris, see www.worldenergyoutlook.org.

[9] Hadley, S. and A. Tsevtkova (2008). Potential Impacts of Plug-in Hybrid Electric Vehicles on Regional Power Generation. Oak Ridge National Laboratory Report ORNL/TM-2007/150, Oak Ridge, TN, USA Jan.2008

[10] Elgowainy, A. et al. Well-to-wheel Energy Use and Greenhouse Gas Emissions of Plugin Hybrid Electric Vehicles. Argonne National Laboratory Report ANL/ESD/10-1, June 2010

[11] F. Sensfuß, Assessment of the impact of renewable electricity generation on the German electricity sector - An agent-based simulation approach, University of Karlsruhe (TH), 2007, Retrieved: 11 July 2011, URL: http://digbib.ubka.unikarlsruhe.de/volltexte/1000007777.

[12] Dallinger D, Wietschel M. Grid integration of intermittent renewable energy sources using price-responsive plug-in electric vehicles. Renew Sustain Energy Rev (2012), doi:10.1016/j.rser.2012.02.019

[13] Elgowainy et al. Impact of Plug-in Hybrid Electric Vehicle Charging Choices in 2030. Paper no. 3800 of the 91st Annual Meeting of the Transportation Research Board, Washington, DC Jan. 2012.

[14] Duvall, M. Transportation Electrification: A Technology Overview. Electric Power Research Institute Report 1021334. Palo Alto CA July 2011.

[15] J. Nitsch, T. Pregger, Y. Scholz, T. Naegler, M. Sterner, N. Gerhardt, A. Von Oehsen, C. Pape, Y. Saint-Drenan, B. Wenzel, Langfristszenarien und Strategien für den Ausbau der erneuerbaren Energien in Deutschland bei Berücksichtigung der Entwicklung in Europa und global, Deutsches Zentrum für Luft- und Raumfahrt, Fraunhofer Institut für Windenergie und Energiesystemtechnik, Ingenieurbüro für neue Energien, vol. BMU - FKZ0, 2010, Retrieved: 11 July 2011, URL: http://www.erneuerbareenergien.de/files/pdfs /allgemein/application/pdf/leitszenario2009 kurzfassung_bf.pdf.

[16] Wang, J. et al. Impact of plug-in hybrid electric vehicles on power systems with demand response and wind power. Energy Policy 39 (2011) 4016-4021.

[17] METI, Strategic Technology Roadmap (Energy Sector) - Energy Technology Vision 2100, Ministry of Economy, Trade and Industry, 2006, Available at: http://www.iae.or.jp/2100/main.pdf.

[18] Moawad, Ayman, Gurhari Singh, Simeon Hagspiel, Mohamed Fellah, and Aymeric Rousseau. 2009. "Impact of Real World Drive Cycles on PHEV Fuel Efficiency and Cost for Different Powertrain and Battery Characteristics." conference paper EVS24. Retrieved: 11 July 2011, URL: http://www.transportation.anl.gov/pdfs/HV/5 64.pdf.

[19] J. Gonder, A. Simpson, Measuring and Reporting Fuel Economy of Plug-In Hybrid Electric Vehicles. The World Electric Vehicle Association Journal, Vol. 1, 2007.

[20] D. J. Santini, A. D. Vyas, J. L. Anderson, Fuel Economy Improvement via Hybridization vs Vehicle Performance Level. FuelFuture Car Congress 2002 (paper 02FCC-125, Arlington), Retrieved: 11 July 2011, URL:

http://cta.ornl.gov/TRBenergy/trb_document s/santini_fuel_economy.pdf, 2002.

[21] U.S. Department of Energy. Energy Efficiency and Renewable Energy Website. Buying Green Power, Retrieved: 11 July 2011, URL http://apps3.eere.energy.gov/greenpower/ buying/ (accessed Feb. 7, 2012).

[22] Green Car Congress. OnStar and Google demonstrate concept service for managing charging Chevrolet Volts with renewable energy 23 January 2012, Retrieved: 11 July 2011, URL:

http://www.greencarcongress.com/2012/0 $\underline{\text { 1/onstar-20120123.html }}$

[23] Carson, P. Energy storage and policy. California regulators hear from interested parties Intelligent Utility, Feb 07, 2012; Available at: http://www.intelligentutility.com/article/12/02 lenergy-storage-and- 
policy\&utm medium $=\mathrm{eNL} \& u$ tm campaign $=\mathrm{I}$ $\underline{\text { U DAILY2\&utm term }=\text { Original-Magazine }}$

[24] van Roekel, A. Unconventionals are easy to find but hard to get. European Energy Review. 16 January 2012. , Available at: http://www.europeanenergyreview.eu/site/pag ina.php?id=3462

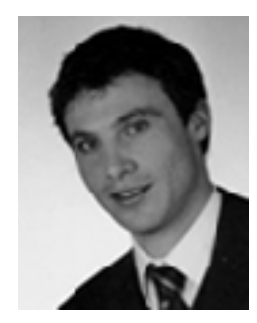

David Dallinger studied business engineering at the Jena University of Applied Sciences. He completed his dissertation and was subsequently employed at ABB (High Voltage) in Switzerland and China. He holds an MSc in Renewable Energies and Energy Efficiency from the University of Kassel. He has been working at the Fraunhofer ISI in Karlsruhe as a research assistant since April 2008.

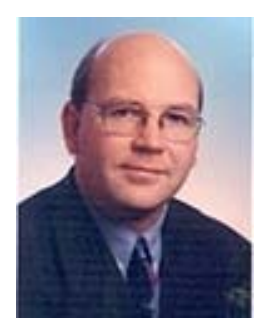

Martin Wietschel studied industrial engineering and management at the University of Karlsruhe. He has been a member of the Competence Center Energy Policy and Energy Systems at the Fraunhofer Institute for Systems and Innovation Research since 2002, where he is the head of the research group focused on energy economy. He teaches at KIT and the ETH in Zürich.

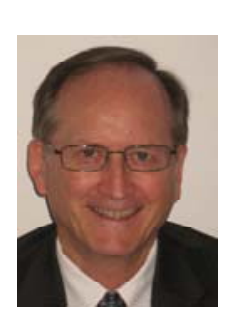

Dr. Danilo J. Santini is a Senior Economist at Argonne National Laboratory. He was chair of the Alternative Fuels Committee of the U.S. Transportation Research Board from 1996-2002; is now Emeritus. Since 2001 he was a representative for the U.S. DOE to the IEA Implementing Agreement on Electric and Hybrid Vehicles, where he leads a study of PHEVs. In 2010 he was awarded the SAE Barry McNutt prize for Excellence in Automotive Policy Analysis for work on PHEVs.
The submitted manuscript has been created in part by Chicago Argonne, LLC, Operator of Argonne National Laboratory ("Argonne"). Argonne, a U.S. Department of Energy Office of Science laboratory, is operated under Contract No. DE-AC0206CH11357. The U.S. Government retains for itself, and others acting on its behalf, a paid-up nonexclusive, irrevocable worldwide license in said article to reproduce, prepare derivative works, distribute copies to the public, and perform publicly and display publicly, by or on behalf of the Government. 